\title{
Optimal Pricing of Green Agriculture Products in a Marketing-Mix Program
}

\author{
Jing Zhang ${ }^{1}$, Shizhen $\mathrm{Bai}^{1 *}, \mathrm{Na} \mathrm{Xu}^{2}$ \\ ${ }^{1}$ School of Business, Harbin University of Commerce, Harbin 150028, China \\ ${ }^{2}$ School of Management, Shandong Technology and Business University, Yantai 264005, China
}

Corresponding Author Email: baishzh@hrbcu.edu.cn

https://doi.org/10.18280/ijsdp.150704

Received: 27 April 2020

Accepted: 1 September 2020

\section{Keywords:}

preselling, spot selling, dynamic pricing, marketing-mix program

\begin{abstract}
China has made great efforts to support high-quality development (HQD) of green agriculture. In recent years, a marketing-mix program involving both preselling and spot selling of green agricultural product has gained popularity across the country. Considering the driving effects of high-quality green agricultural products in supermarket and the difference between preselling and spot selling consumers in product valuation, this paper optimizes the dynamic pricing of the seller of green agricultural products in the preselling period and the spot selling period. The results show that the seller could raise the preselling price and lower the spot selling price, if the product has a prominent driving effect; the seller could raise both preselling and spot selling prices, if the product is perceived by consumers as worthy of waiting for in the supermarket; such a marketing-mix program is suitable for products popular among most consumers. The research findings help enhance the awareness of HQD among enterprises of green agricultural products.
\end{abstract}

\section{INTRODUCTION}

Nowadays, green agricultural products are increasingly popular among consumers. In China, green agricultural products must strictly follow the standards on green food through production and marketing, and pass the certification by China Green Food Development Center. To be certified as green food, an agricultural product must come from purely natural environment, and contain no synthetic substance.

In 2019, China sold nearly USD 8 billion worth of green agricultural products domestically, and exported over USD 4 billion worth of such products to foreign countries. The development of green agricultural products has brought good economic, social, and ecological benefits.

The Chinese government has made great efforts to support high-quality development (HQD) of green agriculture. For example, the Ministry of Agriculture and Rural Affairs listed the development of green agricultural products a key task of rural work in 2020, aiming to make green agricultural products a new source of profits for farmers.

However, many farmers hesitate to invest in green agricultural products, due to the serious imbalance between the supply and demand of agricultural products. This problem could be alleviated if the demand for green agricultural products is clear. Hence, preselling, which allows consumers to place orders before the products are ready, has gained popularity in the consumption of green agricultural products across China [1-3]. This selling mode has been successfully implemented for green agricultural products like Wuchang Rice, and Haerxin vegetables.

Despite the benefits of preselling, some sellers still choose to sell high-quality green agricultural products in supermarkets. These products are welcomed by supermarkets for their driving effect: high-quality green agricultural products can attract high-end consumers to the supermarket, and promote extra consumption.

Haerxin, a well-known green agriculture enterprise in northern China, sells high-quality green agricultural products both through preselling and spot selling in supermarket. In 2019 , the enterprise saw its spot sales growing by $20 \%$ in its own Haerxin Supermarkets and Zhongyanghong Supermarkets.

Previous studies have shown that the same product is perceived to be more valuable among preselling consumers than among spot selling consumers [4, 5]. The prices of preselling and spot selling affect the utility of consumers, causing differences in payment time and purchasing decision. Besides, the spot selling price has an impact on the sales in the regular selling period, and continues to affect the extra consumption induced by the driving effect. Then, the sellers of green agricultural products must make dynamic pricing of their products, considering both the driving effect of spot selling and the preference of preselling consumers.

This paper extends the classic newsvendor model to consider an entire selling season, which consists of two periods (i.e. a marketing-mix program): a preselling period where the sales and purchases are made online before the products are ready, and a spot selling period where sales and purchases are made in the supermarket after the products hit the market. The purchase behaviors of consumers and the decisions of the seller were characterized and modeled in each of the two periods. Then, the dynamic price decisions were optimized to help the seller maximize his/her profit. The main contribution of our research is that: the seller's dynamic pricing was optimized in view of the driving effect of highquality green agricultural products in spot sales, as well as the difference between preselling and spot selling consumers in product valuation. 
The remainder of this paper is organized as follows: Section 2 reviews the relevant literature; Section 3 describes the research problem; Section 4 establishes and solves the mathematical model; Section 5 carries out a numerical analysis; Section 6 puts forward the conclusions.

\section{LITERATURE REVIEW}

Preselling refers to the sales strategy that the sellers begin to accept orders before the products officially hit the market. The consumers are often required to pay a part or all the price in advance [4]. In the early days, preselling was mostly adopted in industries with limited supply of products/services, namely, ticketing, clothing, and reservation services [6].

Preselling is increasingly popular among sellers, owing to the uncertainty of market demand. Through preselling, the seller can learn the product demand timely, and adjust the production plan and selling price as per the number of orders.

Weng and Parlar [7] were the first to study the correlation between preselling and production decision. They analyzed the connotations of preselling and its impact on production decision. Considering the stochasticity of preselling demand, Tang et al. [8] discussed how the update of presale information affects the seller interests. Through modeling and empirical analysis, Moe and Peter [9] measured the impact of the presale of new product on the prediction of market demand. Bernstein and DeCroix [10] investigated how the acquisition of different kinds of demand information in advance affect corporate profit and the benefit brought by flexible allocation of resources. Under uncertain supply and demand, Cho and Tang [11] verified the impact of three sales strategies on manufacturer profit: preselling, regular selling, and dynamic selling, and optimize the conditions for each strategy. Based on the demand in the preselling period, Papier [12] improved the resource allocation in enterprises with limited production capacity, evaluated the value of preselling information, and proposed the optimal way to utilize such information. Karle and Möller [13] suggested that information disclosure helps to reduce the mismatch between consumer preferences and product features, enabling the seller to offer greater discount and boost the sales in preselling period.

The impact of preselling model on seller pricing has long been a research hotspot. Xie and Shugan [14] proposed a normative model, which optimizes the price decision by issuing early announcements to clarify the pre-order conditions. Desiraju and Shugan [15], Shugan and Xie [16] also explored the price decision under the preselling model. Moe and Peter [9] measured the impact of the preselling of new product on the prediction of market demand, with the aid of models and empirical data. Kuthambalayan et al. [17] evaluated the effect of preselling discount on seller profit in a production environment, featured by short cycle, multiple product categories, changing demand, and limited production capacity. Under the constraint of production capacity, Huang et al. [18] constructed a two-stage pricing model for preselling, and deduced the optimal price decisions in the preselling period and the regular selling period.

In addition, Alexandrov and Bedre-Defolie [19] likened the preselling model to the bundling model, and formulated the optimal price decision. Drawing on the laws of the futures market, Noparumpa et al. [20] analyzed the pricing strategies of winemakers, especially under uncertain quality. Xiao et al. [21] investigated the equilibrium pricing strategies and price commitment scheme of the seller under dynamic price, in the light of uncertain product quality and consumer fitness in the preselling period. Under the framework of rational expectation, Peng et al. [22] studied price guarantee policies through preorder-dependent social learning. Wei and Zhang [5] introduced the preorder contingent production (PCP) strategy to curb the negative influence of strategic consumer behavior in preselling market. Niu and Yang [23] discussed the impact of preselling strategies on a three-echelon supply chain, when the upstream enterprises launch a new product for strategic consumers under social influence.

Inspired by the previous studies, this paper characterizes the consumer decisions in the preselling and spot selling periods, and optimize the price decisions of the seller, in consideration of the difference in consumer behaviors and the driving effect of high-quality green agricultural products.

\section{PROBLEM DESCRIPTION}

Our problem involves a typical seller plants and sells highquality green agricultural products through both preselling and spot selling. In the preselling period, the seller accepts online preorders; in the spot selling period, the seller releases its products to the supermarket. Similar to Nasiry and Popescu [24], and Wei and Zhang [5], the authors assumed that all consumers are present in the preselling period, each of which is infinitesimally small in the market, and that the market size is 1 . The consumer valuation of the product $v$ is heterogeneous in nature, and distributed uniformly between 0 and 1 . Since preselling consumers are the first to purchase the product, the valuation discount factor $\sigma$ was introduced [5]. Then, $\sigma v(0<\sigma<1)$ reflects the valuation discount perceived by the consumers in the spot selling period.

The seller-consumer interaction was considered a sequential-move game. The seller aims to maximize his/her profit in the preselling and spot selling periods. Before the preselling period, the seller determines his/her preselling price $p_{1}$ at time $T_{0}$. Next, all consumers decide whether to make the purchase in the preselling period. At the end of the preselling period $T_{l}$, the seller collects the preorders $q_{1}$, predicts the sales $q_{2}$ in the spot selling period, and determines his/her overall planting scale $q\left(q=q_{1}+q_{2}\right) q$. After that, the seller sets the spot selling price $p_{2}$ for the supermarket at the beginning of the spot selling period $T_{2}$. Then, the consumers will choose to make the purchase or not depending on their net surpluses. The strategic decision sequence of the seller is illustrated in Figure 1.

In the spot selling period, extra consumption might occur if consumers purchase high-quality green agricultural products in the supermarket. For example, a consumer could probably buy some pork after he/she purchased the desired green pepper, such as to prepare shredded pork with pepper and soy. In this case, the high-quality green agricultural product green pepper exerts its driving effect.

Focusing on the driving effect of spot selling, this paper mainly investigates the case that the yield of agricultural products surpasses the preordered quantity. For simplicity, it is assumed that the variable production cost equals zero, and that unsold products are discarded at the end of the spot selling period [11]. Then, the driving effect of high-quality green agricultural products was measured by a factor $k$, which boosts the sales in the spot selling period via the consumption of each unit of high-quality green agriculture products. 


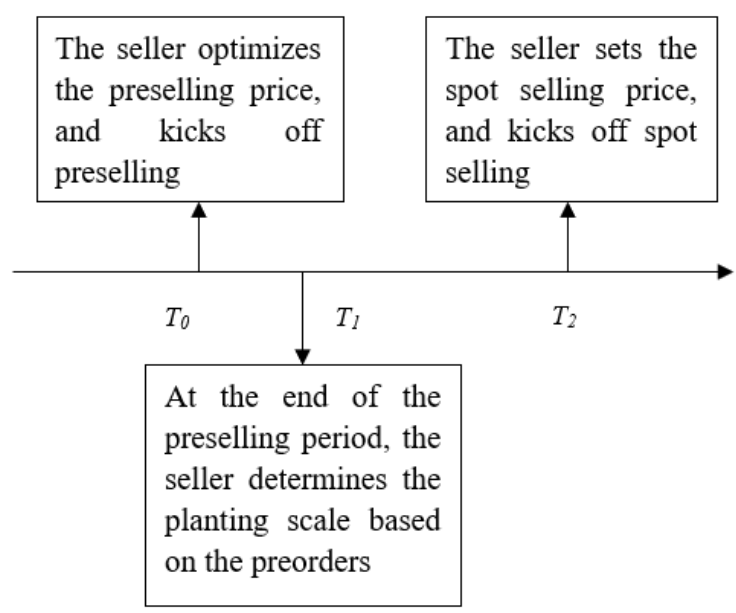

Figure 1. The strategic decision sequence of the seller

\section{MODEL CONSTRUCTION AND SOLVING}

\subsection{Consumer behavior and demand realization}

According to the classic theory on consumer choice, a consumer will make purchase at price $p$ only if his/her net utility, $v-p$, is nonnegative [1]. Hence, the purchase probability is $\operatorname{Prob}\left(v>p_{1}\right)$ in the preselling period, and $\operatorname{Prob}\left(\sigma v>p_{2}\right)$ in the spot selling period. The demand $q_{2}$ in the spot selling period can be derived from the preorders $q_{l}$ in the preselling period:

$$
q_{2}=\left(p_{1}-\frac{p_{2}}{\sigma}\right)^{+} \cdot \frac{q_{1}}{1-p_{1}}
$$

\subsection{Optimal dynamic price decisions}

This subsection optimizes the seller's dynamic price decisions through standard backward induction. Firstly, the optimal spot price was obtained first for the spot selling period. The seller profit in the spot selling period can be maximized by solving:

$$
\begin{aligned}
& \pi_{2}\left(p_{1}, p_{2}\right) \\
& =\max _{p_{1}>p_{2} / \sigma}\left(p_{2}+k\right) \cdot q_{2} \\
& =\max _{p_{1}>p_{2} / \sigma}\left(p_{2}+k\right) \cdot\left(p_{1}-\frac{p_{2}}{\sigma}\right) \cdot \frac{q_{1}}{1-p_{1}}
\end{aligned}
$$

Whereas $\frac{\partial^{2} \pi_{2}}{\partial p_{2}{ }^{2}}=\frac{-2 \cdot q_{1}}{1-p_{1}}<0$ and $\frac{\partial \pi_{2}}{\partial p_{2}}=\frac{q_{1}}{1-p_{1}} \cdot\left(p_{1}-2 \frac{p_{2}}{\sigma}-\frac{k}{\sigma}\right)$, the seller's optimal price decision and corresponding profit can be obtained as in Lemma 1.

LEMMA 1. In the spot selling period, the seller will set his $/$ her price at $p_{2}=\frac{\sigma p_{1}-k}{2}$, produce $q_{2}=\left(\frac{p_{1}+k / \sigma}{2}\right) \cdot \frac{q_{1}}{1-p_{1}}$ units of product, and obtain the maximum spot selling profit $\pi_{2}=$ $\frac{\sigma\left(p_{1}+k / \sigma\right)^{2} q_{1}}{4\left(1-p_{1}\right)}$

The next step is to analyze the seller decision on preselling price. From Lemma 1, the seller's total profit $\pi$ from the two periods can be expressed as:

$$
\pi=\max \left\{\pi_{1}+\pi_{2}\right\}=\max \left\{p_{1} q_{1}+\pi_{2}\right\}
$$

Drawing on the classic demand curve theory, the demand in the preselling period was described as $q_{1}=a-b p_{1}$, where a is the market size, and $b$ is the price sensitivity of consumers. Then, the optimal price decision-making problem of the seller was transformed into the maximization of seller profit by optimizing $p_{I}$ :

$$
\pi\left(p_{1}\right)=\max \left\{p_{1}\left(a-b p_{1}\right)+\frac{\sigma\left(p_{1}+k / \sigma\right)^{2}}{4\left(1-p_{1}\right)} \cdot\left(a-b p_{1}\right)\right\}
$$

The first and second derivatives of profit with respect to price can be respectively obtained as:

$$
\begin{gathered}
\frac{\partial \pi}{\partial p_{1}}=a-2 b p_{1}+\frac{\sigma}{4} \cdot\left[\frac{2\left(a-b p_{1}\right)\left(p_{1}+k / \sigma\right)}{\left(1-p_{1}\right)}+\frac{\left(p_{1}+k / \sigma\right)^{2}(a-b)}{\left(1-p_{1}\right)^{2}}\right] \\
\frac{\partial^{2} \pi}{\partial p_{1}^{2}}=-2 b+\frac{\sigma}{2\left(1-p_{1}\right)^{2}} \cdot\left[\left(1-p_{1}\right)\left(a-2 b p_{1}-b k / \sigma\right)\right. \\
\left.+\left(a-b p_{1}\right)\left(p_{1}+k / \sigma\right)+\frac{(a-b)\left(p_{1}+k / \sigma\right)(1+k / \sigma)}{1-p_{1}}\right]
\end{gathered}
$$

To satisfy the above assumption, the market size was set to $a=1$. For simplicity, the value of $\mathrm{b}$ was set to 1 to derive an analytical solution. Then, it can be obtained that $\frac{\partial^{2} \pi}{\partial p_{1}{ }^{2}}=-\frac{3}{2}<$ 0 , i.e. there exists an optimal preselling price that maximizes the profit under $\frac{\partial \pi}{\partial p_{1}}=0$. Then, the optimal price and profit of the seller can be summed up as the following proposition.

Proposition 1. If $\sigma>2 k /(k+1)$, the preselling price and spot selling price can be respectively expressed as:

$$
\begin{gathered}
p_{1}^{*}=\frac{k+2}{4-\sigma} \\
p_{2}{ }^{*}=\frac{\sigma k+\sigma-2 k}{4-\sigma}
\end{gathered}
$$

In the two periods, the market demand can be respectively expected as:

$$
\begin{aligned}
& q_{1}^{*}=\frac{2-k-\sigma}{4-\sigma} \\
& q_{2}^{*}=\frac{1+2 k / \sigma}{4-\sigma}
\end{aligned}
$$

Under the above circumstances, the optimal seller's total profit can be expected as:

$$
\pi^{*}=\frac{1+k^{2} / \sigma+k}{4-\sigma}
$$

In Proposition 1, the critical condition $\sigma>2 k /(k+1)$ indicates that the spot selling consumers have a high valuation of the products. This is consistent with our assumption that the highquality green agriculture products have a driving effect.

Corollary 1. (1) $\partial \mathrm{p}_{1}{ }^{*} / \partial \mathrm{k}>0, \partial \mathrm{p}_{2}{ }^{*} / \partial \mathrm{k}<0$; (2) $\partial \mathrm{p}_{1}{ }^{*} / \partial \sigma>0$, $\partial \mathrm{p}_{2}{ }^{*} / \partial \sigma>0$. 
Corollary 1 shows that the seller can raise his/her preselling price and lower the spot selling price, if the product has a prominent driving effect.

Different consumers have different demands for the specific properties of the products. To improve net profit per unit of product, the seller tends to focus on the few high valuation consumers by raising the preselling price, and then attract the remaining consumers by offering a low spot selling price.

In addition, the seller can raise both prices, if the product is perceived by consumers as worthy of waiting for in the supermarket. Such a product is the said high-quality green agricultural product with a high value of $\sigma$, which can attract more consumers to the supermarket.

In this way, the seller can capture the high-end consumers with a high preselling price, and the ordinary ones with a low spot selling price. Needless to say, the spot price increases with the product value $\sigma$ perceived by consumers.

Corollary 2. $\partial \pi^{*} / \partial \mathrm{k}>0, \partial \pi^{*} / \partial \sigma>0$.

Corollary 2 shows that the seller's total profit increases with the driving effect factor $k$, as well as the valuation discount factor $\sigma$. As required by China's national policy, enterprises ought to promote the HQD of agriculture. The primary requirement of HQD is to continuously improve the quality of products/services. Without high-quality products, it is impossible to enhance brand influence, not to mention cultivating the driving effect of products.

\section{NUMERICAL ANALYSIS}

This section numerically analyzes how the seller's price decision, expected sales, and profit are affected by the driving effect of high-quality green agricultural products and the valuation discount of products. The relevant parameters were configured as follows: market size $a=1$, and price sensitivity of consumers $b=1$. Figures 2-4 show the influence of driving effect on price, expected sales, and profit, respectively, when the valuation discount factor in the spot selling period is $\sigma=0.8$, and the driving effect factor $k$ varies from 0.1 to 0.6 . Figures 5-7 show the influence of valuation discount on price, expected sales, and profit, respectively, when $k=0.3$, and $\sigma$ varies from 0.5 to 1 .

As shown in Figures 2-4, the growing preselling price reduced the preselling sales and profit, while enhancing the driving effect of high-quality green agricultural products. In the spot selling period, the spot selling price decreased, but the seller profit increased, with the growing expected sales and profit. The more prominent the driving effect, the greater the gap between the preselling and spot selling prices. Therefore, if the product has a strong driving effect, the seller can set a high price threshold to divert consumers to the spot selling channel.

As shown in Figures 5-7, a high valuation discount of highquality green agricultural products in the spot channel pushed up the price and dragged down the expected sales in both periods. Then, the preselling profit dropped, while the spot selling profit grew, resulting in an increase in the seller's total profit. High quality is the foundation of high price. HQD of agricultural products is obviously good to the seller. In addition, the above marketing-mix program, which involves both preselling and spot selling, is suitable for products welcomed by most consumers.

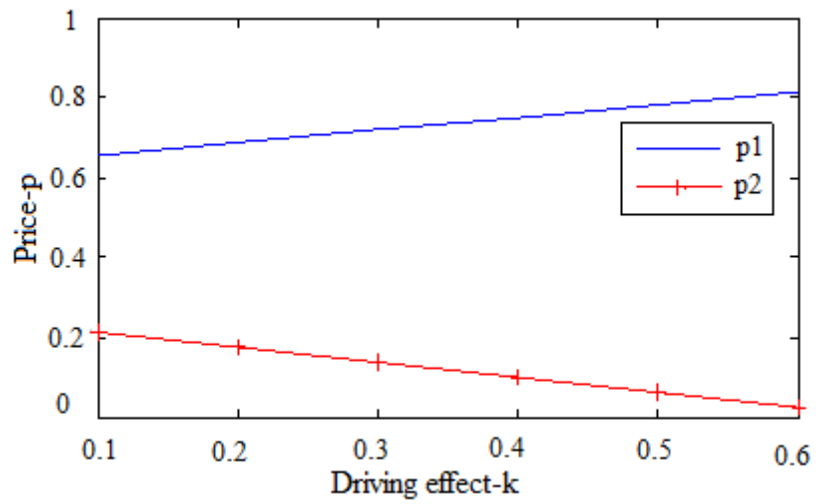

Figure 2. The influence of driving effect on price

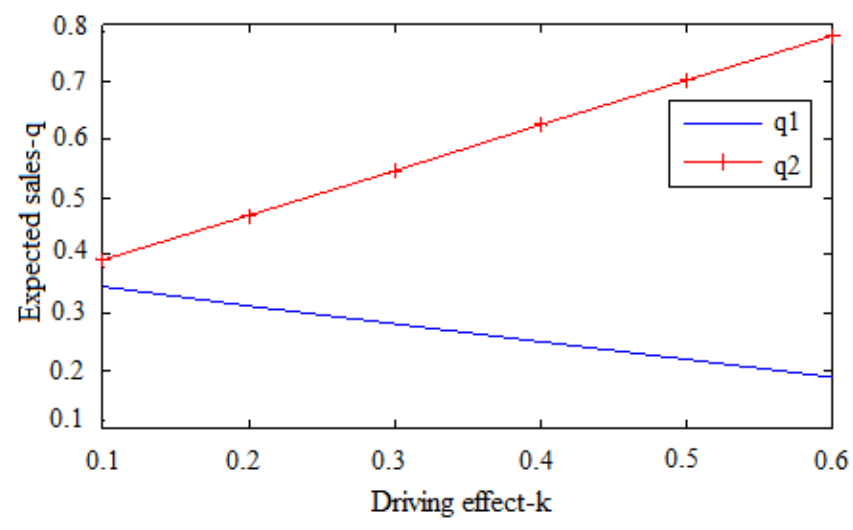

Figure 3. The influence of driving effect on expected sales

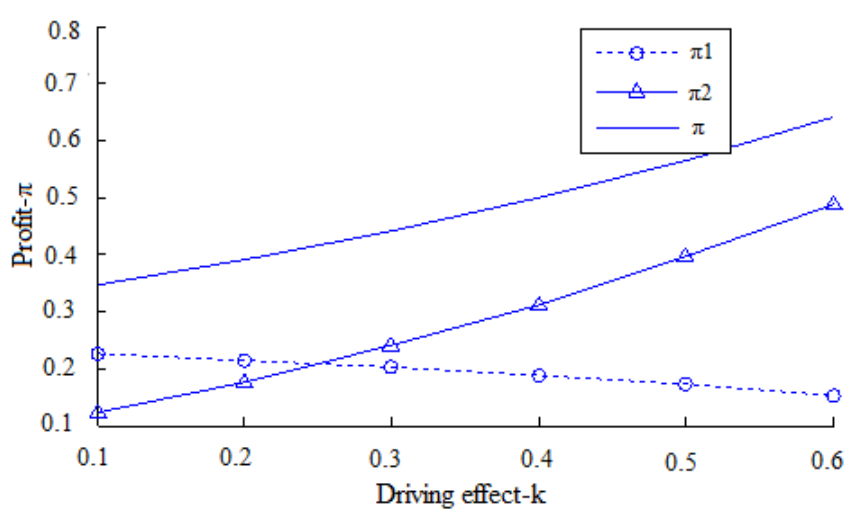

Figure 4. The influence of driving effect on profit

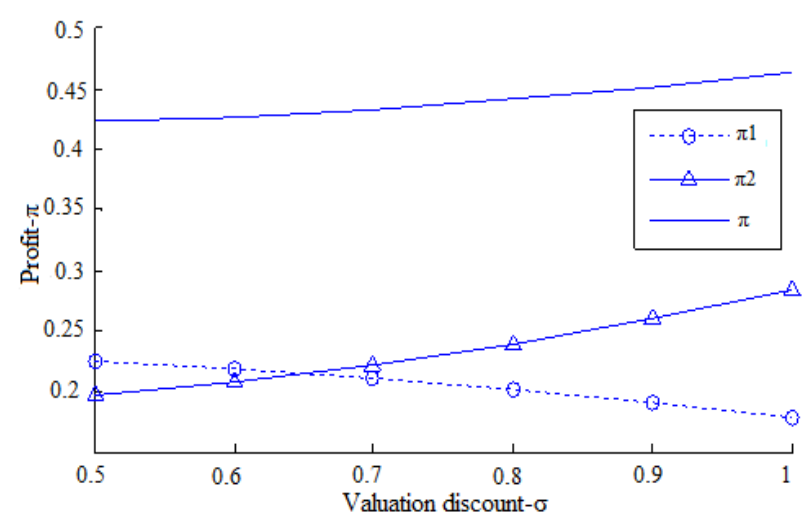

Figure 5. The influence of valuation discount on profit 


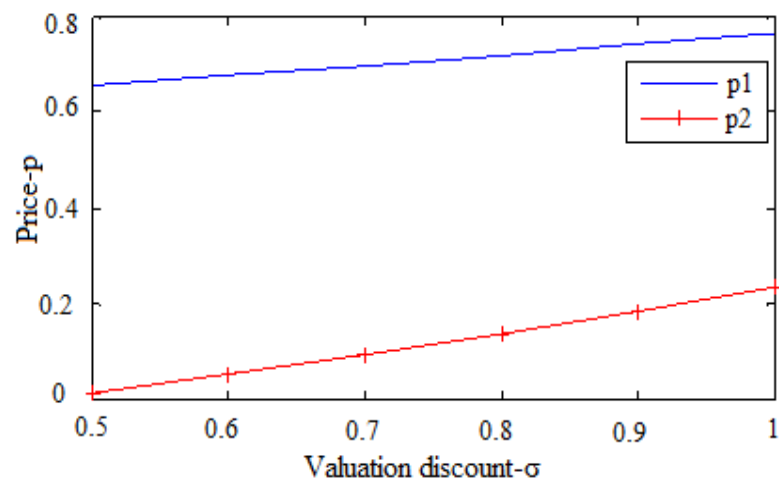

Figure 6. The influence of valuation discount on price

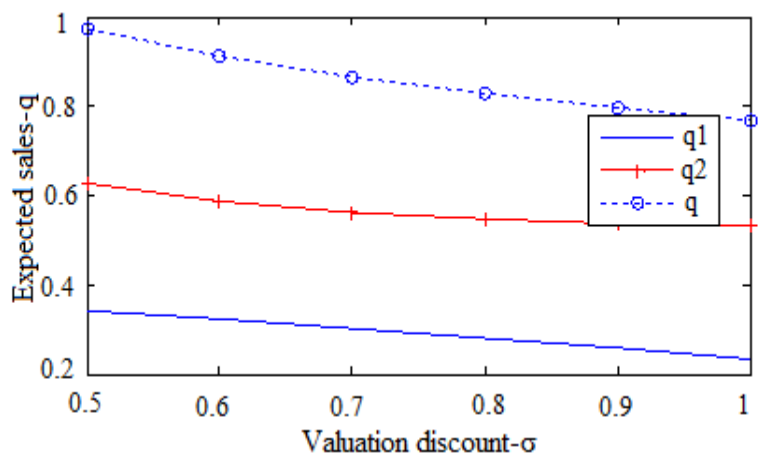

Figure 7. The influence of valuation discount on expected sales

\section{CONCLUSIONS}

This paper mainly solves the optimal price decision-making problem of the seller for both preselling and spot selling. Special considerations were given to the different value perceptions of consumers in the two sales channels, as well as the driving effect of high-quality green agricultural products. The results show that the seller could raise the preselling price and lower the spot selling price, if the product has a prominent driving effect; the seller could raise both preselling and spot selling prices, if the product is perceived by consumers as worthy of waiting for in the supermarket; such a marketingmix program is suitable for products popular among most consumers. These findings help enhance the awareness of HQD among enterprises of green agricultural products, enabling them to make more profit with the proposed marketing-mix program. The future research will explore the optimal price decision-making problem with statistic demand and production of green agriculture products.

\section{ACKNOWLEDGMENTS}

This work was supported by the National Natural Science Foundation of China (Grant No.: 71671054, 2017) and Philosophy and Social Sciences Research Planning Project, Heilongjiang Province, China (Grant No.:20GLB114, 2020).

\section{REFERENCES}

[1] Prasad, A., Stecke, K.E., Zhao, X.Y. (2009). Advance selling by a newsvendor retailer. Production and
Operations $\quad$ Management, 20(1):

$129-142$.

https://doi.org/10.2139/ssrn.1375222

[2] Cheng, Y.S., Li, H.Y., Anders, T. (2018). Advance selling with double marketing efforts in a newsvendor framework. Computers \& Industrial Engineering, 118: 352-365. https://doi.org/10.1016/j.cie.2018.03.006

[3] Wu, M., Zhu, S.X., Teunter, R.H. (2020). Advance selling and advertising: A newsvendor framework. Decision Science. Online, 1-34. https://doi.org/10.1111/deci.12423

[4] Li, C.H., Zhang, F.Q. (2013). Advance demand information, price discrimination, and preorder strategies. Manufacturing \& Service Operations Management, 15(1): 57-71. https://doi.org/10.1287/msom.1120.0398

[5] Wei, M.M.C., Zhang, F.Q. (2018). Advance selling to strategic consumers: preorder contingent production strategy with advance selling target. Production \& Operations Management, 27(7): 1221-1235. https://doi.org/10.1111/poms.12863

[6] Wang, T., Toktay, B.L. (2008). Inventory management with advance demand information and flexible delivery. Management Science, 54(4): 716-732. https://doi.org/10.1287/mnsc.1070.0831

[7] Weng, Z.K., Parlar, M. (1999). Integrating early sales with production decisions: Analysis and insights. IIE Transactions, 31(11): 1051-1060. https://doi.org/10.1023/A:1007671407701

[8] Tang, C.S., Rajaram, K., Alptekinoğlu, A., Ou, J.H. (2004). The benefits of advance booking discount programs: Model and analysis. Management Science, 50(4): 465-478. https://www.jstor.org/stable/30046086

[9] Moe, W.W., Fader, P.S. (2002). Fast-track: article using advance purchase orders to forecast new product sales. Marketing Science, 21(3): 347-364. https://doi.org/10.1287/mksc.21.3.347.138

[10] Bernstein, F., DeCroix, G.A. (2015). Advance demand information in a multiproduct system. Manufacturing \& Service Operations Management, 17(1): 52-65. https://doi.org/10.1287/msom.2014.0502

[11] Cho, S.H., Tang, C.S. (2013). Advance selling in a supply chain under uncertain supply and demand. Manufacturing \& Service Operations Management, 15(2): https://doi.org/10.1287/msom.1120.0423

[12] Papier, F. (2016). Supply allocation under sequential advance demand information. Operations Research, 64(2): 341-361. https://doi.org/10.1287/opre.2015.1465

[13] Karle, H., Möller, M. (2019). Selling in advance to loss averse consumers. International Economic Review, 61(1): 441-468. https://doi.org/10.1111/iere.12429

[14] Xie, J.H., Shugan, S.M. (2001). Electronic tickets, smart cards, and online prepayments: When and how to advance sell. Marketing Science, 20(3): 219-243. https://doi.org/10.1287/mksc.20.3.219.9765

[15] Desiraju, R., Shugan, S.M. (1999). Strategic service pricing and yield management. Journal of Marketing, 63(1): 44-56. https://www.jstor.org/stable/1252000

[16] Shugan, S.M., Xie, J.H. (2000). Advance pricing of services and other implications of separating purchase and consumption. Journal of Service Research, 2: 227239. https://doi.org/10.1177/109467050023001

[17] Kuthambalayan, T.S., Metha, P., Shanker, K. (2015). (2015). Managing product variety with advance selling and capacity restrictions. International Journal of 
Production Economics, 170: 287-296. https://doi.org/10.1016/j.ijpe.2015.10.006

[18] Huang, K.L., Kuo, C.W., Shi, H.J. (2017). Advance selling with freebies and limited production capacity. Omega, 73:

18-28. https://doi.org/10.1016/j.omega.2016.12.002

[19] Alexandrov A., Bedre-Defolie, Ö. (2014). The equivalence of bundling and advance sales. Marketing Science, 33(2):

259-272. https://doi.org/10.1287/mksc.2013.0833

[20] Noparumpa, T., Kazaz, B., Webster, S. (2015). Wine futures and advance selling under quality uncertainty. Manufacturing \& Service Operations Management, 17(3): $\quad$ 411-426. https://doi.org/10.1287/msom.2015.0529

[21] Xiao, L., Xu, M.H., Chen, Z.Y., Guan, X. (2019). Optimal pricing for advance selling with uncertain product quality and consumer fitness. Journal of the Operational Research Society, 70(9): 1457-1474. https://doi.org/10.1080/01605682.2018.1489342

[22] Peng, W., Tian, Z., Wang, Y. (2020). Price guarantee for advance selling in the presence of preorder-dependent social learning. International Journal of Production Economics, 219:

https://doi.org/10.1016/j.ijpe.2019.05.015

[23] Niu, Q.Y., Yang, F. (2020). The impact of advance selling strategies on a three-echelon supply chain in the presence of social influence. Mathematical Problems in Engineering, 2020: NA.

[24] Nasiry, J., Popescu, I. (2012). Advance selling when consumers regret. Management Science, 58(6): 11601177. https://doi.org/10.1287/mnsc. 1110.1473

\section{NOMENCLATURE}

V Product valuation in preselling period

$\sigma$

a

b

$\mathrm{p}_{1}$

$\mathrm{q}_{1}$

$\mathrm{q}_{2}$

$\mathrm{p}_{2}$

$\mathrm{k}$

$\pi$ Valuation discount factor in spot selling period, $0<\sigma<1$

Market size

Price sensitivity of consumers

Preselling price

Sales in preselling period

Sales in spot selling period

Spot selling price

Driving effect of high-quality green agricultural product in the supermarket Seller's total profit 